\title{
Customised Customer Support Using a Soft Computing Approach
}

\author{
S Shah \\ R Roy \\ A Tiwari \\ B Majeed \\ Cranfield University \\ Cranfield University \\ Cranfield University \\ BT Plc \\ s.shah@cranfield.ac.uk \\ r.roy@cranfield.ac.uk \\ a.tiwari@cranfield.ac.uk \\ b.majeed@bt.com
}

\begin{abstract}
This paper describes the research and development of a methodology to identify the type of information required by the service advisor (CSA) within customer contact centre (CCC) environment. Data was collected through case studies carried out within five customer contact centres to derive the categories for customers and advisors based on demographic, experience, business value and behavioural attributes. We provide the methodology to develop a fuzzy expert system which assigns a new customer or advisor to the predefined categories. The authors have explained the steps which were followed for the development of the fuzzy expert system. A prototype system has been designed and developed to identify the type of customer and CSA based on the demographic, experience and behavioural attributes. The authors illustrate analysis with real data, based on the work with large scale customer contact centres. Validation of the information requirement model was carried out at the contact centres.
\end{abstract}

\section{Introduction}

In a time of fast growing technology and communication systems, it is important for industry and organisations to develop new customer contact centre (CCC) environment technologies for better customer satisfaction. There are three features of contact centre operations that customers feel are crucial to quality service, namely convenience in fast call handling, cordiality of the advisor, and consistency in advisors providing a reliable and accurate service [1]. It is critical for companies to identify the need to offer a superior service in order to ensure business survival in a service sector economy [2]. Customer contact centres afford the companies the potential to manage customer relations more effectively, thus providing some competitive advantage while saving costs [3]. Customer satisfaction may in addition be based on another three dimensions: access, including the advisors communication skills; timeliness, including advisors resolution of queries; and quality, which includes the accuracy, consistency and comprehensiveness of the advisors advice, in addition to the knowledge and politeness of the advisors. Thus the role of the advisors, assumes a heightened importance in customer satisfaction [4]. Within the current contact centre environment there is a problem of high staff turnover and lack of trained staff at the right place for the right kind of customer. Business needs to assign any available advisor to a customer and provide consistent and good quality of service. There is a need to identify the right amount of information to be displayed on the screen considering both the customer and the assigned advisor background.

\section{Related Research}

Research in understanding customer preferences, known as 'consumer behaviour study', has been the subject of investigation in psychological marketing area for few decades. Understanding and adapting to changes of customer behaviour is an important aspect of surviving in a continuously changing environment [6]. Customer choice of a product depends on explicit requirements, implicit requirements, available options and latent requirements implied by the product [7]. The performance of a CSA during interactions with customers has been the subject of considerable research, in both sales and service settings [8]. Research has suggested that advisors (CSA's) performance is critical to create customer satisfaction, little has been done to analyse which employee behaviour influence customer encounter satisfaction and which behaviour influence relationship satisfaction. Previous studies also suggest that attitudinal and behavioural responses of advisors are important because of the interactive nature of service delivery. It also showed that advisors attitudinal and behavioural responses can positively and negatively affect customer's perceptions of the service encounter and their judgments of service quality [9]. Trust has a moderate but beneficial influence on the development 
of positive customer attitudes, intentions, and behaviour. Advisors (CSA) have modest influence over the development of trust between themselves and their customer [9]. Customer attitude is influenced by belief about brand equity (value), which is affected by the content, context and infrastructure. Customer loyalty is determined by attitude and belief about the context in which the products or services are offered [10]. Modeling the users can include statements of how the users within a specific user group behave in certain situations or perform certain functions [11]. Emotional reactions to a sales interaction may affect consumer satisfaction with the purchase experience and future purchase intentions (cross - up sell opportunities) [12].

Soft computing differs from hard (conventional) computing in that it is tolerant of imprecision, uncertainty and partial truth [13]. Soft computing technologies provide an approximate solution to an ill defined problem and can create user models in an environment such as contact centre to identify: (a) customer willingness to buy (b) companies prediction towards customer purchase intentions (c) advisor reaction towards customer attitude and (d) customer behaviour towards advisors communication [14].

\section{Current Practice}

For the purpose of this research, the authors organised visits to three different customer contact centres (CCC) and interviewed 20 advisors and 6 team leaders. The data and information collected from these centres were captured, understood and were combined with the current information obtained from the literature review and, they were used to identify the categorisation for customer and advisor. The main objectives were:

- Identify the current understanding of the customer contact centre environment, its overall operation and working.

- Identify the current bottlenecks in the business process.

- Identify the use of different customer - advisor characterisation procedures.

\subsection{Key Observations and Findings}

The primary key targets for the centres noticed by the authors were mainly the RAP time which is the time the advisor spent other than on calls. Call times takes up about 2 minutes to 12 minutes. Call Handling Time is the effective time; the advisor spends on calls with the customers. The findings showed that there was a high turn over of CSA and it was necessary to allocate the first available advisor to the customer and then provide the advisor with relevant information. The technical issues encountered during the visits to the centres are as discussed below in table (1).

Table1. Contact Centre Observations and Findings

\begin{tabular}{|l|l|l|l|}
\hline \multicolumn{1}{|c|}{ Issues } & Company A & \multicolumn{1}{c|}{ Company B } & \multicolumn{1}{c|}{$\begin{array}{c}\text { Company } \\
\text { Cystem }\end{array}$} \\
\hline $\begin{array}{l}\text { Functiona } \\
\text { lities }\end{array}$ & $\begin{array}{l}\text { Complex } \\
\text { systems. }\end{array}$ & $\begin{array}{l}\text { Long time } \\
\text { needed on } \\
\text { training }\end{array}$ & $\begin{array}{l}\text { Wrong } \\
\text { calls } \\
\text { transferred } \\
\text { through } \\
\text { IVR. }\end{array}$ \\
\hline $\begin{array}{l}\text { Advisor } \\
\text { (CSA) } \\
\text { Overview }\end{array}$ & $\begin{array}{l}\text { Time spent on } \\
\text { arrangement } \\
\text { of work once } \\
\text { the call is } \\
\text { finished }\end{array}$ & $\begin{array}{l}\text { Wrong calls } \\
\text { been dealt by } \\
\text { the advisor }\end{array}$ & $\begin{array}{l}\text { More time } \\
\text { spent on } \\
\text { search of } \\
\text { information }\end{array}$ \\
\hline $\begin{array}{l}\text { Customer } \\
\text { Overview }\end{array}$ & $\begin{array}{l}\text { Understand } \\
\text { the delay }\end{array}$ & $\begin{array}{l}\text { Unsure the type } \\
\text { of problems } \\
\text { encountered. }\end{array}$ & $\begin{array}{l}\text { Lack of } \\
\text { sufficient } \\
\text { information }\end{array}$ \\
\hline $\begin{array}{l}\text { Call } \\
\text { Problems }\end{array}$ & $\begin{array}{l}\text { Customer } \\
\text { calls without } \\
\text { knowing the } \\
\text { service } \\
\text { required. }\end{array}$ & $\begin{array}{l}\text { Wrong } \\
\text { department calls } \\
\text { which are } \\
\text { needed to be } \\
\text { transferred. }\end{array}$ & $\begin{array}{l}\text { Long } \\
\text { queues of } \\
\text { calls with } \\
\text { long wait } \\
\text { times }\end{array}$ \\
\hline
\end{tabular}

\section{Cranfield Approach - Research Methodology}

Through the proposed methodology for categorisation of customer and advisor, the authors have demonstrated a way which can help to identify the right amount of information which can enable the advisor to deal with the customer more efficiently and thus providing better customer satisfaction. The main sections which are discussed here for the development of the information requirement methodology are:

1. Data Collection - Study to identify the industrial context and need for information requirement framework.

2. Clustering Analysis - For categorisation of customer and advisor.

3. Development of Fuzzy Expert system -.For assigning any customer and advisor with a predefined category.

4. Information Requirement Analysis - To identify the required information to be displayed on the screen depending on the customer and advisor 


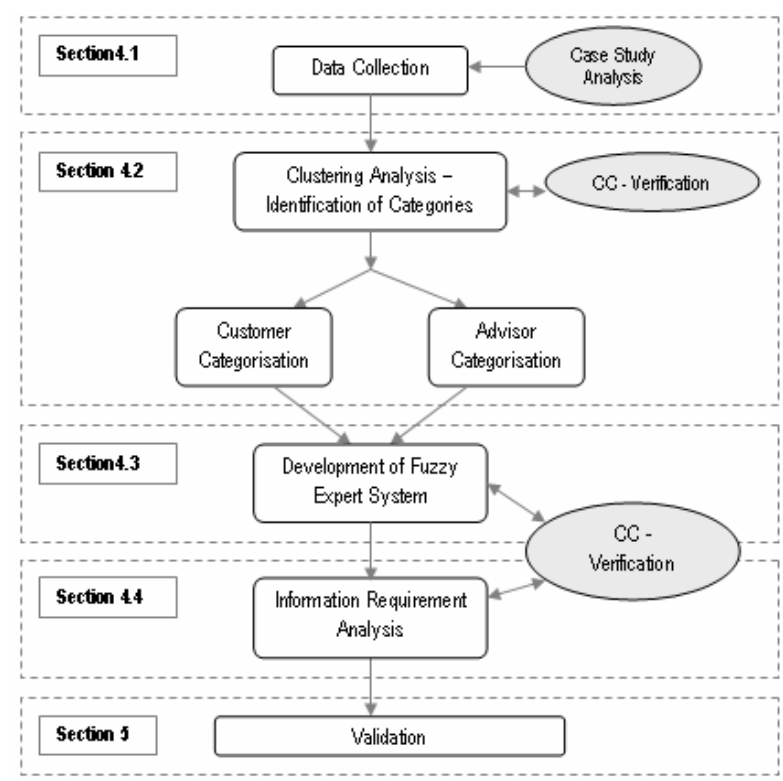

Figure 1. Flowchart for the proposed methodology

AS-IS study was done at five of the customer contact centres to identify the current trends in customer contact and the need to identify the right amount of information considering both the customer and assigned advisor background. Data was collected with semi structured questionnaire for advisors and team leaders at contact centres. Proper methodology was followed for the development of fuzzy expert system for the assignment of category to the advisor and customer. Experimental results were carried out within the model to identify the type of category assigned to each customer and advisor which was validated with the experts. For full explanation of the development of the methodology refer to reference [16].

For information requirement analysis; possible combinations of \{customer, advisor\} scenarios were derived. Based on these possible scenarios, the minimum amount of information required to be displayed was derived. The team leaders and managers were thus given the option of all the possible combinations of the customer and advisors, and asked to identify information which would help the advisor to serve the customer. Further design and development of the information required framework is discussed in section 4.4. Validation of information requirement framework was done through expert judgments from team leaders and discussed in section 5 .

\subsection{Data Collection}

Data was collected with the help of semistructured questionnaires for advisors (CSA) and team leaders/managers with respect to their demographic variables, experience and behavioural variables within five customer contact centre focusing on fault and sales and looking on single to multi profile business customers. A total of 84 advisors were interviewed and assessed, 60 customer calls were monitored, and total of 19 team leaders and managers were interviewed through the questionnaires. The key observations which the authors noticed for the data collection were advisors characteristics and customer monitoring (voice). Please refer to reference [16] for full list of the criteria's used for customer and advisor data collection. The customer data collection was done on the basis of the information provided on the screen of the advisor when the call conversation was in progress. Based on the data collection and analysis of data; attributes derived for customer and advisor are as follows:

- Customer - age, education, financial status, time with company, business value and behavioural analysis.

- Advisor - age, education, experience, previous experience, IT speed, and behavioural analysis.

Through the data analysis tool, the customers and advisor were then grouped according to the attributes shared among each other.

\subsection{Clustering Analysis - Identification of Customer and Advisor Categorisation}

This section shows the method followed for identification of customer and advisor categorisation through clustering analysis by using two - step process within SPSS analysis. The final set of attributes used for customer and advisor (CSA) for the clustering analysis to derive the categories are as shown in table (2). Six advisor categories (A1-A6) were derived out of the 84 data sets for the advisors. Based on the clustering few results were noted which were:

1. Because the number of clusters increased from $6-10$, the total number of cases each cluster is taking is not properly distributed.

2. The rules derived from the cluster results are repeated and are too close to each other. 
TABLE 2. ADVISOR AND CUSTOMER ANALYSIS [16]

1. Age-young, Advisors (CSA)

2. Education - school, college, graduate, professional

3. Experience - novice, medium, senior

4. IT Speed - slow, medium, fast

5. Previous Exp - low, moderate, extensive

6. Positive Behaviour - attentive, friendly, customer focus

7. Negative Behaviour - unaware, annoyed, angry

1. Age - young, middle age, old

2. Education - school, college, graduate, professional

3. Financial Status - poor, average, good

4. Time with Company- low, moderate, high

5. Business Value - low, medium, high

6. Positive Behaviour - joyful, co-operative, understanding

7. Negative Behaviour - angry, annoyed, aggressive

\subsection{Development of Fuzzy Expert System}

This section discusses the steps followed for the development of the fuzzy expert system to assign any customer and advisor to that of pre-defined category which was derived from the clustering analysis.

Step 1 - Identify the critical factors and define membership functions and fuzzy sets.

The critical factors were the input variables of the fuzzy ES which were as age, gender, and education, and financial background, time with the company, business value and behaviour from the customer side which would identify the type of category they belong to. Triangular and trapezoidal types of membership function are selected to define the variables (figure 2).

\section{Step 2 - Construct the Fuzzy Rules}

Within the fuzzy expert system model once the membership functions for customers and advisors were derived, fuzzy if...then rule were written which identified the type of input for customers and advisors. The rule base specifies qualitatively how the output of the system "Category" for the advisor and the customer is determined for the input variables of Age, Education, Financial Status, and Time with Company, Business Value, and Experience. A total of twenty rules were derived within the expert system. For advisor rules; IF age is young, education is school, experience is novice, previous exp is low, IT speed is slow, positive behaviour as friendly and negative behaviour as unaware THEN the selected category is A1.
For customer rules; IF age is young, education is school, financial status is poor, time with company is

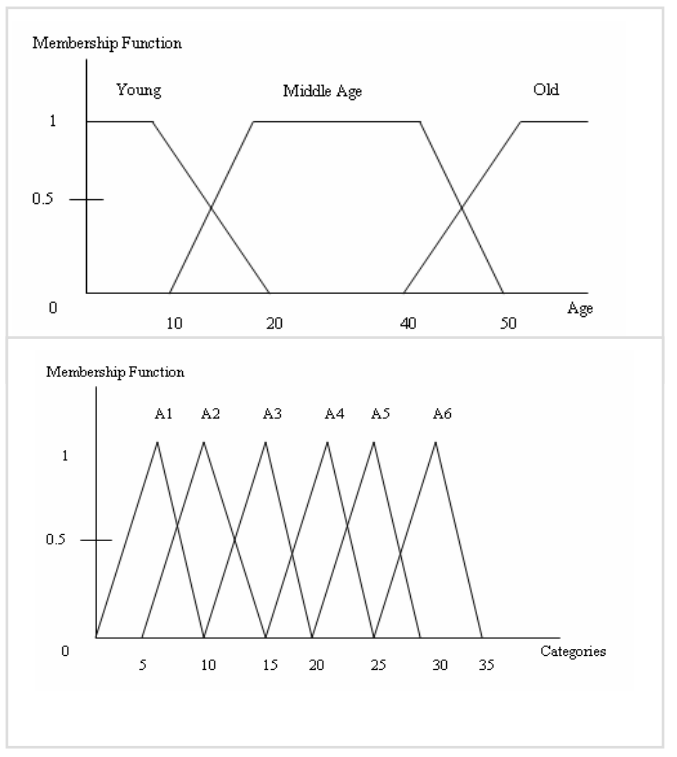

Figure. 2. Sample Membership Functions for Input (Age) and Output (Categories) of the System [15]

low, business value is low, positive behaviour is none and negative behaviour is aggressive THEN the category selected is $\mathrm{C} 1$.

\subsection{Information Requirement Analysis}

Information requirement analysis was done on the basis of the set of categories for customer and advisor derived from the clustering and determined from the fuzzy expert system model. The main objective was to identify the minimum amount of information which is required to be displayed on the screen to the advisor which would enable the advisor to help the customer. This information should always satisfy the three important business aspects of customer contact which were (i) Customer Satisfaction, (2) Resolving the conflict and (3) Cross Sell - Up Sell opportunities. Information Requirement framework was developed to overcome the information overload with the current contact centre environment. Also from the point of customer satisfaction speed of response was crucial and the right amount of information which is required to be displayed to the advisor under particular customer - advisor situation was important. 


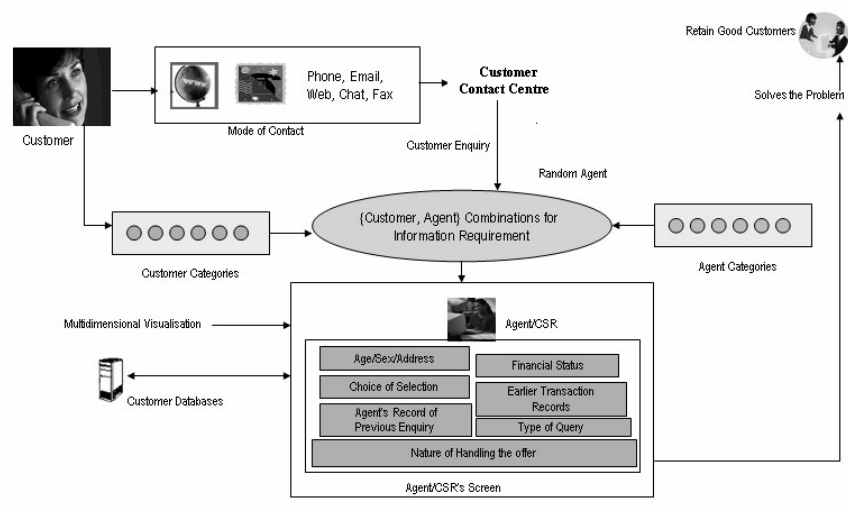

Figure 3. Conceptual Contact Centre Model

From the initial understanding of the contact centre, and from the literature studies; the author designed a template with the complete list of information which would be used during a particular customer-advisor conversation. This list is mainly divided into three sections with customer information, business service details and advisor details (figure 4). Once the total information to be displayed was known, it was validated with the industry experts of six team leaders and three advisors within the centre.

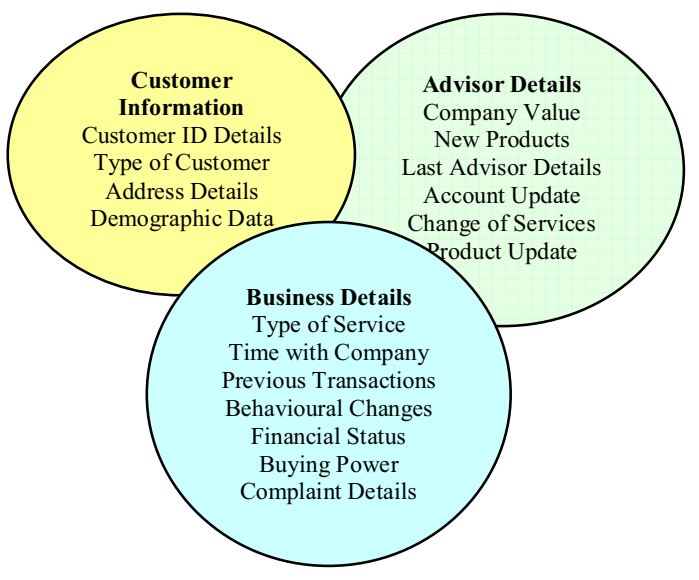

Figure 4. Contact Centre Information

\section{Validation}

The information and the results from the model were verified through team leaders and managers at three of the contact centres. A total of nine team leaders and managers were interviewed with the help of an open set questionnaire, showing the categories derived and the assignment of a particular customer or advisor to these categories through the help of the fuzzy expert system tool developed. From the validation, it was noticed that the expert judgment did correspond to that of the results from the expert system model framework for $80 \%$ of the overall experiments that were carried out. A total of thirty six scenarios were considered identifying the best case and worst case of customer and advisor contact. The scenario identifies the type of customer and advisor and selects the required information based on the customer and advisor attributes from the categorisation [16].

Example 1. Worst Advisor - Best Customer Scenario (Advisor A1 and Customer C4)

A1 - Female, 18-25, School (education), >1yrs Experience, Slow (IT speed), None Previous experience, Angry and Unaware (behaviour)

C4 - Female, 40+ (age), Professional (education), Average (financial status), 10-12 yrs (time with company), High (business value), Joyful (behaviour)

Information to Display - Customer ID, address details, customer type, time with company, buying pattern/power, financial status, type of services, payment options, new products and services

Example 2. Best Advisor - Worst Customer Scenario (Advisor A5 and Customer C1)

A5 - Male, 50+ (age), Professional (education), 10+ yrs (experience), Medium (IT speed), Moderate (prev.exp.), Friendly (behaviour)

C1 - Female, 18-25, School (education), Poor (financial status), 1-5 yrs (Time with company), Low (business value), Angry and Aggressive (behaviour)

Information Display - Customer ID, address details, type of customer, payment options, financial status, type of services, business value to company, customer complaints

\section{Discussion and Future Research}

The authors have demonstrated the steps which were followed to identify the information requirement analysis for the advisor within contact centre environment. The need to identify the right amount of information to be displayed on the screen for both customer and the assigned advisor background led to the development of the research framework. Experimental results were carried out which showed that $80 \%$ of time the model was assigning a particular customer and advisor to the [16]. The cost and maintenance analysis of the framework would be considered for future research and will form the part of the continuing research carried out within the project. Further validation of the framework will be carried out with simulation techniques. 


\section{Conclusions}

This paper is focused on the research and development of methodology to identify the right amount of information to be displayed on the screen. Four main approaches were followed for the development of the information requirement methodology. The AS-IS study was carried out to study and identify the industrial context and the need of the framework. The authors identified the initial attributes through five case studies carried out at the customer contact centres within UK ranging from telecoms to help desk and government with 84 customer advisor and 60 customers' data points. Based on the initial clustering results, the authors then derived the initial categorisation for customers and advisors. Development of fuzzy expert system was carried out to assign any customer or advisor to that of the predetermined category from the clustering analysis. The fuzzy expert system was validated with the experts from CC with experimental results showing the assignment of the categories to customer and advisors. Information requirement framework was validated with nine team leaders and advisors at the contact centres.

\section{Acknowledgments}

The authors wish to acknowledge the support of the Engineering and Physical Sciences Research Council (EPSRC), British Telecommunication Plc, and Decision Engineering research team (DEG) in the Enterprise Integration department at Cranfield University; UK

\section{References}

[1] Haymarket Business Publications (1998). The telebusiness report - the definitive report on telebusiness in the UK to the year 2005. Marketing Direct Magazine. April 1998. PP 5-17

[2] Prabhaker, R; Sheehan, J; Coppett, J (1997). The power of technology in business selling: call centres. Journal of Business and Industrial Marketing. Vol 12. Issue $3 / 4$. PP 220-232

[3] Connon, E (1996). Developing and retaining profitable customer relationships through call centres. Direct Marketing. Vol 59. Issue 5. PP 24-26

[4] Brown, Gavin and Maxwell, Gillian (2002) Customer service in UK call centres: organisational perspectives and employee perceptions. Journal of Retailing and Consumer Services Vol 92002 PP 309-316

[5] Schmitt, $M$ and Allscheid, S (1995) Employee attitudes and customer satisfaction: making theoretical and empirical connection. Personnel Psychology. Vol 48. Issue 3. PP 521-36.
[6] Chiu, Chaochang (2002). A case based customer classification approach for direct marketing. Expert Systems with Applications. Vol 22 (2002). Pp 163168. Elsevier Science Ltd.

[7] Fung, R.Y; Popplewell, K and Xie, J (1998). An intelligent hybrid system for customer requirements analysis and product attribute targets determination. International Journal of Production Research. 1998. Vol 36. No.1. PP 13-34.

[8] Zeelenberg, Marcel and Pieters, Rik (2004). Beyond valence in customer dissatisfaction: A review and new findings on behavioural responses to regret and disappointment in failed services. Journal of Business Research. Vol 57 (2004). Pp 445-455. Elsevier Science Ltd.

[9] Dolen, Willemijn van; Ruyter, Ko de and Lemmink, Jos (2004). An empirical assessment of the influence of customer emotions and contact employee performance on encounter and relationship satisfaction. Journal of Business Research. Vol 57 (2004). Pp 437-444. Elsevier Science Ltd.

[10] Swan, J; Bowers, M and Richardson, L (1999). Customer trust in the salesperson: An Integrative review and meta-analysis of the empirical literature. Journal of Business Research, Vol 44, Issue 2. PP 93-107

[11] Bushey, R.; Mauney, Jennifer. M and Deelman, Thomas (1999). The development of behaviourbased user models for a computer system. $7^{\text {th }}$ International Conference on User Modeling (UM99). 20 $0^{\text {th }}-24^{\text {th }}$ June 1999. Banff Centre, Banff. Canada. Pp 109-118.

[12] Goff, Brent. G; Boles, James. S; Bellenger, Danny. $\mathrm{N}$ and Stojack, Carrie (1997). The influence of salesperson selling behaviours on customer satisfaction with products. Journal of Retailing. Vol 32. No 2. pp 171-183.

[13] Zadeh, L. (1996). The role of soft computing and fuzzy logic in conception, design and deployment of intelligent systems. Proceedings International Workshop on Soft Computing in Industry, Muroran, Japan, April 1996, pp 136-137.

[14] Ngai, E.W.T and Wat, F.K.T (2003). Design and development of a fuzzy expert system for hotel selection. The International Journal of Management Science. Vol 31. PP 275-86. Elsevier Science.

[15] Shah, Satya; Roy, Rajkumar and Tiwari, Ashutosh (In Press). Development of fuzzy expert system for categorising customer and advisors in contact centres. Submitted to $10^{\text {th }}$ Online World Conference on Soft Computing in Industrial Applications.

[16] Shah, Satya; Roy, Rajkumar; Tiwari, Ashutosh and Basim Majeed (Unpublished). Categorisation of customer and advisor in contact centres. Submitted to European Journal of Operational Research. 